\section{An Adoress}

\author{
ON THE
}

\section{UNSOLVED PROBLENS IN GYNACOLOGY AND OBSTETRIC'S.}

Read by invitution before the American Gyncecological Society on June 2nd, 1921 ,

BY W. BLAIR BELL, B.S., M.D. LOND.,

PROFLSBOR OF OBSTETRICS AND G YY.ECOLOCY TN THE UNIVERSITY; ORSTETRIOAT AND T YNACOLOGICAL GURYEON TO THE ROY $A L$ INHRMLRY ; ORSTETRICAL SCRICON "O TIY MATE RNITY HOSPITAL, LIESRPOOL.

To-DAY gynæcology and obstetrics stand bigh among the developments of surgery along scientific and specialised lines; yet the more I think of this, the greater is $\mathrm{my}$ wonderment that it should be so. It seems such a short while since our specialties were struggling towards the light. Wlien, therefore, I received your invitation to address this learned society, it occurred to me that it might not be inappropriate if I were to consider for a few moments the principal avenue through which approach may be made to the secrets still hidden from us, and the personnel and equipment required for the task.

I do not think there can be any doubt that the collective status of the gynæcclogists and obstetricians of the world in regard to clinical acumen and surgical technique is nearing the limit which must be set to human achievement, and that the same will soon obtain in regard to the bacteriological aspects of our special subjects.

But in contradistinction to this must be placed the unsatisfactory character of our advancement-- the slow progress we are making-in the more essentially biological, including biochemical, problems, connected not only with the normal morphology and physiology of the female genitalia, but also with the pathological developments that may be associated with the structure and function of the reproductive organs. Concerving the actual details of these problems I shall have but little to say, except by way of illustration.

\section{Educational Methods.}

First, let me consider how far our present methods of education are conducive to the correct mental attitude of the future investigator, whether they are methods that stimulate the powers of perception and make every student an interested observer from the beginning.

It is a curious commentary on the value of the allied sciences to the surgeon of to-day that there is a growing tendency, at any rate in my own country, to minimise the importance of biology and to urge the superior-T might almost say "exclusive" claims of the final hospital study ; and the attitude is not confined to the student. This seems to me unfortunate, for it means that we are catering entirely for men of moderate intelligence and not at all for those on whom may fall the responsibility of sustaining progress in our science. As a result of our existing methods, the clinical aspects of gynæcology and obstetrics have been thoroughly illuminated, as I have said, while the more abstruse biological features are but very imperfectly understood and their claims hardly realised. It may be argued that there are many expert physiologists, biochemists, and comparative anatomists; and this is true, but alone they cannot help us because they do not yet know our difficulties, neither have they the clinical nor technical knowledge with which to guide their steps. Up to the present the teaching of elementary gynæcological anatomy and physiology has been conducted by the clinical instructor, because these subjects have been almost invariably ignored by the physiologist and anatomist. This means, 5104 generally speaking, that expert physiologists and anatomists have remained in rnore or less complete ignorance of these matters, and are, therefore, even now unaware of the hiatuses in our knowledge.

There can be no doubt, I think, that the man who continually has to face difficulties in practice is the one most likely to find the means of circumventing them, provided he have sufficient all-round knowledge and adequate facilities for his task. It is only natural, however, that each should turn his attention to those matters concerning which he is best informed. It is obvious, therefore, that if the many biological problems connected with gynæcology and obstetrics, which so far have baffled us, are to be elucidated we must modify the general plan of education in regard to those who may perchance attempt to throw light on what is now obscure and indistinct.

In attempting to indicate the direction in which educational improvement may be made, I shall doubtless merely give verbal form to what must already have taken shape in the minds of many. In our educational methods we are too apt, I think, to set store on detail. We should, I believe, aim at encouraging a comprehensive and inclusive outlook. We destroy originality by overloading the young mind with so-called facts which often are the easily deducible results of observation. Again, it seems to me that the different subjects of the general curriculum are taught in too disjointed and exclusive a manner. As gynæcologists and obstetricians we should have the right-and the same applies to teacher's in the other branches of final medical study - to define the subjert-matter of the physioiogical and anatomical courses. The anatomist should be required to demonstrate and teach comparative and human anatomy on the lines we desire, and the physiologist should be obliged to lead, by experiment and demonsuration in the laboratory, more directly to what will bo taught later in regard to the human subject. There must, in fact, be more coördination throughout. It would be bettcr, for instance, if the key-subject biology were tauyht in such a way as to make the student realise that in it man is included in a wide generalisation with the lower animals, and that man is but the evolutionary physiological and morphological climax. The student should be more definitely impressed with the knowledge that in his biological and biochemical studies he is watching the evolution of man, that he is following the simple to the complex, and that what may be normal at one stage is pathological in a higher state of evolutionthat hermaphroditism, for example, is normal in the earth-worm but abnormal in man. If the student could be imbued with some conception of the ultimate value of all his biological work, and could be taught not to look upon it as a separate and isolated obstacle to arrest his onward course, not only would his hospital studies be more interesting and more relatively important, but his mental attitude and outlook would be as much fitted for the investigation of biological as for the study of purely clinical problems.

The Wider Sclentific Mentaltix.

The present trend, then, of medical education in Great Britain has been towards the production of good clinicians, rather than of men with their minds alive to the biological-morphological and physiological, including biochemical-import of the phenomena they observe. I often wonder how far this question has been realised in America, this training of the student towards a wider scientific mentality. In Great Britain, where general practitioners are now being urged to coöperate in an investigation concerning the beginnings of disease, it is clear that there is a need of reform in our methods of education if we are to expect results on the lines I have indicated.

Supposing, howerer, that the student has been educated on these principles, in what circumstances and in what environment will he find inspiration, 
and obtain the best results? The establishment and success of clinical units and of units for groupstudy in North America and Canada may provide the answer. Their foundation is, of course, open to the interpretation that these systems have been brought into existence because the brain of the average intelligent man is incapable of grasping and understanding all the side issues that go to make up the sum of medical knowledge; and I have heard it stated by an advocate of them that this is their raison d'être. Moreover, it is said that only in them can material properly be utilised and the one-line worker find an immediate use for his output. While the last part of this statement is true, $I$ cannot agree entirely with the first. A properly educated man of wide perception is not necessarily a man of encyclopædic knowledge, but, rather, one whose mind is so saturated with basic principles that the mosaic of detail falls into an orderly pattern under the influence of his prescient intelligence. A man with the index type of mind is rarely original, and is not, therefore, necessarily worthy of encouragement. I have already referred to this in regard to the education of the student.

Pasteurs are, of course, born not made, but I believe that useful imitations can be developed by proper education and training, imitations good enough in the helpful environment of which I have just spoken to obtain results. Because the great biological and medical discoveries in the past have emanated from the brains of men ploughing a lonely furrow, there is no inherent reason why men of similar intellect should not again arise and in the more perfect environment that can be assured to-day unravel the outstanding questions. Meanwhile it should be possible now for men of lesser ability with proper education and a perfect environment to surmount difficulties which the master-minds of the past, with their more limited opportunities, could not orercome.

I would once more urge the importance, so well recognised in this country, of clinical work going hand in hand with scientific laboratory investigations. You have many wise foundations, whereas we are sadly handicapped for want of them. We in Great Britain who are interested in the scientific aspects of our subjects have not the same facilities.

In this continent there is offered subsequently to the well-educated man every opportunity for attacking these problems at a living wage; but in Great Britain we cannot always secure the best men for the service of science, for we cannot offer them a reasonable financial reward, a reward in any way commensurate with that to be obtained from practice. This is a matter that is exercising us greatly, for times are changing, and while clinical matters are so well established that they can take care of themselves, there is urgent need that further progress which, as I have stated is largely biological, should not be crippled and hampered for want of proper organisation in teaching and post-graduate research.

If, then, the last ramparts of gynæcological and obstetrical diseases are to be captured we must modify to some extent our methods of education and we must bring correlation, breadth, and inspiration into the musty empiricism of the preliminary studies. I know the curriculum is overcrowded, but it is mostly with what could well be spared. We must, also, encourage scientific enterprise, and after educating our students for their life-work give them the opportunity of utilising their talents and of advancing the science of obstetrics and yynæco$\log y$.

I shall now endearour briefly to substantiate my statement that the great outstanding problems in gynæcology and obstetrics are biological in the narrowest sense of the word.

\section{Morphological Problems.}

The development of the human ovary can now be described with a considerable degree of certainty, but the same cannot be said in regard to that of the genital passages. To what factors, for instance, is due the fusion of the Müllerian ducts in the genital cord? This is of considerable importance in connexion with the common so-called malformations of the uterus and vagina. Prof. Wood Jones, who has done so much excellent work on the comparative anatomy of the genital organs, believes that we should look upon these conditions of imperfect union as atavisms rather than malformations; and in this light the comparative anatomy of the genitalia becomes both interesting and instructive. Indeed it is from this point of view alone that information can be obtained. If serial sections be cut of the divided and uniting uterine horns in various species of rodentia and carnivora, all the later stages in the development of the human uterus may be seen. Moreover, it will be made clear that the human uterus has morphologically but two muscular coats and not three, as usually described. Nevertheless, we do not yet know what determines the final development of the human uterus, and we can hardly expect to know until we have decided definitely what are the variations in the factors that lead to the difierent degrees of Miillerian union that are normal. constant phenomena in closely related animals. In rodents there may be seen the complete didelphic condition with double vagina (viscacha) and the gradual evolution to the single vagina and bicornute uterus (agouti).

Again, can the peritoneal pouch that encloses the ovarian extremity of the tube and ovary itself, a structure seen in certain rodents, and, as I have found in a less complete form in hedgehogs, be passed over as a freak structure, in spite of the fact that, as Bland-Sutton has shown, it may exist as an atavism in woman? It seems to me that a structure so useful to fertilisation and conception is worthy of serious study, especially from the point of view of the state of peritoneal currents and other influences in the creatures concerned. An investigation concerning the nature of the secretion of these sacs would also be of consiluerable intersst.

Let me take another matter which, possibly, is of more clinical importance. How far are we familiar with the causes of the irregularities in the female hony polvis, apart from those resulting from gross postnatal disease, such as ricket:? We talk about civilisation, athletics, and the rest, but what cause: a generally contracted pelvis in a welldeveloped non-rachitic woman who has been guilty of none of the enterprises that militate against functional perfection?

The work of Whitridge Williams and others has demonstrated beyond reasonable doubt that the typical funnel-shaped pelvis is associated with high assimilation, but $I$ do not think the cause of high assimilation is definitely known. Such an important matter, especially in this country, is deserving of extensive systematic investigation. Comparative racial studies, in which different races are examined in their natural environments, might throw considerable light on this and on other pelvic abnormalities. There can be no doubt that civilisation may greatly affect structure as well as function.

As a last morphological point of interest-albeit there are many others that will occur to all-let me say that I look forward to the day when some gynæcologist or obstetrician will give us the clue to the mode of origin of pathological new growths. After all the gynæcologist and obstetrician has, time and again, given a lead to the rest of the profession: and in the problem to which I refer he is on his own ground, for his work is chiefly concerned with the preservation of the structures and functions through the medium of which neoplastic derelopments normally occur.

Physionogical Problems.

It is within the last 20 years that practically all the recognised facts concerning the female functions have been discovered. We now know, if I may quote one of my own aphorisms, that a woman is a woman on account of all her internal secretions 
and not only because she possesses ovaries. But we still lack certain evidence as to the nature of the controlling force that determines the primary sexcharacteristics of the person concerned; nor do we know how it comes about that even in the course of development a conjunction of sex-characteristics may occur, a condition of hermaphroditism. Even if it be that the masculinity or femininity balance of the internal secretions is disturbed, this is still an effect, not a cause. That this fascinating and intricate problem is capable of solution I am convinced. It may well be the life-work of someone capable of estimating the gradual changes through the numerous classes of creatures that indicate the evolutionary origin of man-of some comparative morphologist with all the histological technique of the present at his disposal on which to graft new methods of observation; and then. when the gross serial steps have been demonstrated, he may perchance gain an inkling of that on which they depend, an inkling of the force which imbues the fertilised ovum of man with maleness and femaleness.

There are few, surely, who cannot recognise to-day the vast importance of femaleness as opposed to maleness, and few, too, who are not conversant with the essential physiological-that is to say, biochemical-differences that influence the mind and body. We have, too, some knowledge of what constitutes puberty. It is, we believe, the time of life when the metabolism has met the claims of somatic growth. The potentiality of a girl's metabolic resources at this time is such that it can support the strain of reproduction and all that this involves. But we do not know what happens at puberty to start the new train of events. What is the hormone that makes the ovary aware of the situation; is it then that the genital functions of the ductless gland come into being, and, if so, what leads to this awakening? That it is not a habit of life is too obvious to need discussion; it is due, rather, to a series of chemical events that may be altered and delayed by many circumstances of health and environment.

\section{Nature of Menstruation.}

Then, again, have we established without the possibility of fallacy the nature of menstruation? My view that it is an excretory process in regard to the principal elements required during pregnancy for the building up of the foetus, and during lactation for the formation of milk, as is made evident by the calcium metabolism, requires full confirmation and elaboration in regard to the exact part played by the ovaries and other internal secretions.

To pass on, I would ask if there is general agreement concerning the factors involved in the production of the climacteric? I myself, for instance, disagree with those who think that the normal menopause is the result of primary ovarian atrophy, although many of the phenomena of the menopause are due to this change. The fact that the artificial menopause is produced by oöphorectomy has been a blind to all of us. If the ovaries are removed from a young woman with protracted amenorrhoea and ovarian destruction menopausal symptoms do not supervene. The artificial menopause is induced only when there has been pre-existing ovarian activity. At the commencement of the normal menopause the ovaries are normal and active, indeed, at the end of that phenomenon the woman may be capable of conception. Why is it that ovarian substance or extract of any kind, and in any combination whatever and however administered, does not produce specific results at the physiological menopause: whereas whole-gland ovarian substance, especially in association with thyroid substance, gives relief in case in which the menopause has been induced by operative procedures? There are some, I know, who will dispute this; but I believe the facts, as I have stated them, to be true. From this jumble-shall I say ? - of observations it appears justifiable to ask you to consider as a working hypothesis for further investigations the view that there is at the climacteric some substance circulating in the blood, some natural biochemical toxin, or something withdrawn from it, which leads not only to ovarian atrophy but also to the other physiological and structural alterations that take place at the "change of life."

Another group of important correlated functions about which we know but little is that concerned with fertilisation and conception.

\section{Selective Sterility.}

I think that light will soon be shed on that curious anomaly I call "selective sterility." In view of recent additions to our knowledge in regard to the incompatibility of the blood of persons in different groups, it is not unlikely that selective sterility-as well as successful homoplastic, as opposed to autoplastic, ovarian grafting - will be found to depend on a similar, if not identical phenomenon. So far we know that a difference in the blood-grouping of married couples has no obvious relation to the possibility, or otherwise, of conception. Again, the normal inter-relations that exist between the mother and her foetus in utero have been studied to some purpose; but we are still ignorant of the way in which the growing embryo controls the development of the chorionic epithelium that sometimes takes on such disastrous activity when the control is removed.

I do not think the theory that in such circumstances there is lutein over-growth is sufficient. It is common to see vesicular mole and chorion-epithelioma without abnormal lutein development.

\section{Toxamias of Pregnancy.}

Moreover, how little we know concerning the toxæmias of pregnancy. It seems to me that before we can arrive at any proper idea of the disturbance produced we must know far more intimately the normal metabolic mechanism concerned and the maternal forces that are marshalled against the deleterious effects produced by what is, after all, a new growth in the uterus. If the recent work of Dold and Obata concerning eclampsia be correct, as seems possible, we shall be placed in possession of very interesting information concerning a biological phenomenon of vast importance, for I do not doubt that, if it be fully confirmed, we shall be able to test the blood of every pregnant woman before so serious a condition as eclampsia supervenes and to treat her with normal human serum. I have myself seen excellent results with blood-transfusion.

Although hundreds of thousands of human beings are expelled from the uterus daily we have but a faint glimmering of the biochemical factors leading to the determination of parturition. And what of lactation? Is the mechanism of the simple nature I have described in the Sex Complex? If so, we are little in advance of the ancients who, owing to their powers of perception, have always been worthy of consideration in matters of priority.

Such gynæcological and obstetrical problems seem to me almost infinite when I let $\mathrm{my}$ mind wander around the outposts of our small impregnable position of certain knowledge. I have, however, to-day the desire to emphasise not only the importance of those unsolved problems, which we all admit, but also the essential biological nature of them. I have attempted, too, to show that our education tends to drive us forward almost entirely along the deeplytrodden paths rather than along those barely to be seen or yet uncut through virgin country. I would plead, therefore, that our students and our postgraduates be more broadly educated at least in the great principles of biology, for $I$ believe that only by way of physiological, especially biochemical research, and by the comparative study of simpler forms of structure shall we be able to bring our art towards scientific pefection. 